\title{
Common Factors Responsible for Uncontrolled Epilepsy Patients attended at a Tertiary Care Hospital in Bangladesh
}

\author{
Md. Ferdous Mian', Mohammad Enayet Hussain², Md. Nahidul Islam³, AFM Al Masum Khan, \\ Rajib Nayan Chowdhury ${ }^{5}$, Mansur Habib ${ }^{6}$, Quazi Deen Mohammad7 . \\ ${ }^{1}$ Assistant Professor, Department of Neurology, National Institute of Neurosciences \& Hospital, Dhaka, Bangladesh; ${ }^{2}$ Assistant \\ Professor, Department of Neurology, National Institute of Neurosciences \& Hospital, Dhaka, Bangladesh; ${ }^{3}$ Assistant \\ Professor, Department of Neurology, National Institute of Neurosciences \& Hospital, Dhaka, Bangladesh; ${ }^{4}$ Medical \\ Officer, Department of Neurophysiology, National Institute of Neurosciences\& Hospital, Dhaka, Bangladesh; \\ ${ }^{5}$ Associate Professor \& Head, Department of Neurophysiology, National Institute of Neurosciences \& \\ Hospital, Dhaka, Bangladesh; ${ }^{6}$ Professor \& Head, Department of Neurology, Dhaka Medical College, \\ Dhaka Bangladesh; ${ }^{7}$ Fellow neurology. Director\& Professor, Department of Clinical Neurology, \\ National Institute of Neurosciences \& Hospital, Dhaka, Bangladesh
}

[Received: 21 January 2016; Revised: 6 March 2016; Accepted: 11 December 2016; Published: 1 January 2017]

\begin{abstract}
Background: Epilepsy is a common neurological disorder. It is estimated that there are at least 1.5 to 2 million epilepsy patients in Bangladesh3. Many of these patients are suffering from uncontrolled epilepsy which leads to cognitive deterioration, psychosocial dysfunction and increased morbidity and mortality. The causes behind uncontrolled epilepsy are multifactorial. Some are patient-related, some physician-related and some are medication-related. Objective: The purpose of the present study was to identify the factors responsible for uncontrolled epilepsy. Methodology: This case-control study was carried out in the epilepsy clinic of the Dhaka Medical College Hospital, Dhaka, Bangladesh from July 2010 to June 2012 (2 years). A total of 100 patients of which 50 consecutive patients of uncontrolled epilepsy (cases) and 50 age-matched controls with well controlled epilepsy (control) were recruited. Patients were interviewed according to a preformed questionnaire. Results: The mean ages of case and control groups were $21.84 \pm 8.70$ and $23.94 \pm$ 10.28 years $(\mathrm{p}=0.273)$. The male female ratio was almost equal in both groups. The factors which turned out significant ( $p$ value $<0.05$ ) for uncontrolled epilepsy were lack of support from the family ( $p=0.032$ ), lack of motivation about the disease $(\mathrm{p}=0.001)$, unavailability of drugs $(\mathrm{p}=0.001)$, irregular intake of anti-epileptic drugs $(p=0.001)$, stopping AEDs willingly after transient control of seizures $(p=0.001)$, lack of knowledge about the disease $(p=0.003)$, treatment duration $(p=0.005) \&$ prognosis of the disease $(p=0.026)$. Other factors were low annual income of the family $(p=0.001)$, occupation $(p=0.040)$, lower educational status $(\mathrm{p}=0.027)$ and residence in rural area $(\mathrm{p}=0.016)$. Important patient related factors were earlier age of onset of seizure $(\mathrm{p}=0.027)$, higher initial seizure frequency $(\mathrm{p}=0.012)$, associated clinical features (neurological deficits, mental retardation, behavioral abnormality) $(\mathrm{p}=0.030)$, abnormal brain imaging findings $(\mathrm{p}=0.013)$ and non response to first anti epileptic drug $(\mathrm{p}=0.005)$. Conclusion: Many of the factors behind uncontrolled epilepsy can be minimized by proper counseling of the patient at the start of treatment and regular follow up. [Journal of National Institute of Neurosciences Bangladesh, 2017;3(1): 42-47]
\end{abstract}

\section{Keywords: Common Factors; Uncontrolled Epilepsy; Bangladesh}

Correspondence: Md. Ferdous Mian, Assistant Professor, Department of Neurology, National Institute of Neurosciences \& Hospital, Sher-E-Bangla Nahar, Agargaon, Dhaka, Bangladesh; Email: mfm020771@gmail.com; Cell No.: +8801814965306

Conflict of interest: There is no conflict of interest relevant to this paper to disclose.

Funding agency: This research project was not funded by any group or any institution.

Contribution to authors: MFM was involved in study design, sample collection, patient's management, report analysis as well as manuscript writing. MEH, MNI, AFMAMK and RNC were involved in the patient's management, report analysis as well as manuscript writing. MH and QDM were involved in study design and overall supervision.

How to cite this article: Mian MF, Hussain ME, Islam MN, Khan AFMAM, Chowdhury RN, Habib M, Mohammad QD. Common Factors Responsible for Uncontrolled Epilepsy Patients attended at a Tertiary Care Hospital in Bangladesh. J Natl Inst Neurosci Bangladesh, 2017;3(1): 42-47

Copyright: (C2017 Mian et al. Published by Journal of National Institute of Neurosciences Bangladesh. This article is published under the Creative Commons CC BY-NC License (https://creativecommons.org/licenses/by-nc/4.0/). This license permits use, distribution and reproduction in any medium, provided the original work is properly cited, and is not used for commercial purposes. 


\section{Introduction}

Epilepsy is a common neurological problem. World Health Organization has reported that 50 million people are suffering from epilepsy worldwide of which $80.0 \%$ reside in developing countries ${ }^{1}$. A meta-analysis ${ }^{2}$ showed that the median lifetime epilepsy prevalence for developed countries was 5.8 per 1,000. In developing countries prevalence was 15.4 per 1,000 in rural and 10.3 per 1,000 in urban areas ${ }^{2}$.

It is estimated that there are at least 1.5 to 2 million epilepsy patients in Bangladesh3. Many of these patients have uncontrolled epilepsy which may lead to cognitive deterioration, psychosocial dysfunction, and increased morbidity and mortality. There are many factors behind uncontrolled epilepsy including non-compliance of drug, incorrect diagnosis, inappropriate drug, dose and duration and lastly refractory epilepsy ${ }^{3}$. A study on the causes for non-compliance of anti-epileptic drugs therapy in Bangladesh found that non-affordability; limited availability and adverse effects of drugs, inadequate knowledge, negative attitude, lack of counseling are the main causes ${ }^{3}$.

Non-compliance behavior can be expressed as not taking anti-epileptic drugs (AEDs) on time, manipulating dosages, and not following the doctor's advice regarding daily activities ${ }^{4,5}$. Non-compliance is a significant problem in the epilepsy management ${ }^{6}$. Studies regarding non-compliance have found four primary factors associated with medication non-compliance ${ }^{7}$. These are the patient-related factors like socio-economic characteristics, and perceptions and beliefs, illness-related factors like severity of illness and frequency of symptom, medication related factors like number of daily doses, efficacy, and side effects, and physician-related factors like patient-physician relationship ${ }^{8}$. In another study, the factors influencing non-compliance were difficulty in collecting the drug once in 2 weeks from the hospitals, lack of family support, mental adverse effects of the drugs as well as the poor motivation ${ }^{9-10}$.

Another cause of uncontrolled epilepsy is drug-resistance. Drug-resistance epilepsy is stated simply as failure to achieve seizure control despite adequate amount of antiepileptic drug (AED) therapy. The International League against Epilepsy (ILAE) consensus definition of drug resistant epilepsy required 'failure of two tolerated, appropriately chosen and used antiepileptic drug schedules to achieve sustained seizure freedom' either 12 months or three times the longest inter seizure interval ${ }^{11}$. Different risk factors have been associated with drug resistance epilepsy. A history of status epilepticus, infantile spasm, neonatal seizure, microcephaly to be associated with medically intractable epilepsy ${ }^{12}$. Patients having many seizures before treatment and inadequate response to initial treatment are likely to have refractory epilepsy ${ }^{13}$. Abnormal neurological status and early break through attack after treatment initiation were predictors of medically intractable epilepsy. Developmental delay, neurological deficits, high frequency of seizure at onset and abnormal brain imaging were associated with intractability ${ }^{15}$. An absence of Neonatal seizure, older age at onset, normal intelligence, and less than 20 seizures before initiation of treatment were all significant predictors of remission ${ }^{16}$. The present study was undertaken to identify the common factors responsible for uncontrolled epilepsy.

\section{Methodology}

This case-control study was carried out in the Epilepsy clinic of the Department of Neurology at Dhaka Medical College Hospital, Dhaka, Bangladesh from July 2010 to June 2012. A total of 100 patients of which 50 consecutive patients of uncontrolled epilepsy (cases) and 50 age-matched controls with well controlled epilepsy (control) were recruited. Controlled epilepsy was defined as no seizure for more than six months during treatment of epilepsy ${ }^{17}$. Uncontrolled epilepsy was defined as one or more seizures over a period of six months during treatment of epilepsy ${ }^{17}$. The data collection tools were a questionnaire and a structured interview schedule. Questionnaire had both open-ended and closed-ended questions. Data were collected by means of interview with the patients and/or patient's family members. History, clinical features, investigation findings and relevant data were collected by the researcher himself by face to face interview and from records of the patients. Data were processed and analyzed using SPSS version 17.0 software for windows. Both qualitative and quantitative tests were performed. For comparison between groups, Chi square $\left(\mathrm{x}^{2}\right)$ test was performed and for quantitative variables 2 sample t-test was used. The level of significance was set at 0.05 and $\mathrm{P}<0.05$ was considered significant. The summarized data were interpreted accordingly and was presented in the form of tables. Statistical analyses were done by appropriate methods. Prior to the commencement of the study, the research protocol was approved by the Ethical Review Committee (ERC) of Dhaka Medical College. The aims and objectives of the study along with its procedure, methods, risks and benefits were explained to the 
respondent in easily understandable language and then informed written consent was taken from each patient or appropriate guardian. It was assured that all information and records would be kept confidential.

\section{Results}

Most patient were younger ( $<30$ years) in both case and control groups with male preponderance in both groups. t-test was done to measure the level of significance (Table 1).

Table 2 shows the distribution of study population according to educational status, occupation, income status of family and residence. This shows that low education level, unemployment, low income and residence in rural areas are risk factors for uncontrolled epilepsy.

Table 3 shows the earlier is the onset of seizure the more is the risk for seizure of being uncontrolled. Chi-square test was done to measure the level of significance.

Table 4 shows the distribution of patients according to initial seizure frequency. Initial seizure frequency was $>1 /$ day in $18(36.0 \%)$ and $8(16.0 \%)$ in case and control group respectively. It shows the higher the initial seizure frequency the higher is the chance to have uncontrolled seizure. The difference was statistically significant $(\mathrm{p}=0.012)$. Chi-square test was done to measure the level of significance.

Table 3: Distribution of patients according to age at onset of seizure

\begin{tabular}{lccc}
\hline \multirow{2}{*}{$\begin{array}{l}\text { Age at Onset of } \\
\text { Seizure }\end{array}$} & \multicolumn{2}{c}{ Group } & p value \\
\cline { 2 - 3 } Case & Control & \\
\hline 0 to 5 Years & $17(34.0 \%)$ & $5(10.0 \%)$ & \\
6 to 10 Years & $11(22.0 \%)$ & $11(22.0 \%)$ & 0.027 \\
11 to 14 Years & $5(10.0 \%)$ & $9(18.0 \%)$ & \\
More Than 14 Years & $17(34.0 \%)$ & $25(50.0 \%)$ & \\
Total & $\mathbf{5 0 ( 1 0 0 . 0 \% )}$ & $\mathbf{5 0 ( 1 0 0 . 0 \% )}$ & \\
\hline
\end{tabular}

Table 4: Distribution of Patients According to Initial Seizure Frequency

\begin{tabular}{lccc}
\hline Initial Seizure & \multicolumn{2}{c}{ Group } & p value \\
\cline { 2 - 3 } Frequency & Case & Control & \\
\hline$>1 /$ day & $18(36.0 \%)$ & $8(16.0 \%)$ & 0.012 \\
$>1 /$ week & $15(30.0 \%)$ & $14(28.0 \%)$ & \\
1 or $>1 /$ month & $14(28.0 \%)$ & $14(28.0 \%)$ & \\
$<1 /$ month & $3(6.0 \%)$ & $14(28.0 \%)$ & \\
Total & $\mathbf{5 0 ( 1 0 0 . 0 \% )}$ & $\mathbf{5 0}(\mathbf{1 0 0 . 0} \%)$ & \\
\hline
\end{tabular}

Table 1: Distribution of Patients according to Age and Sex

\begin{tabular}{|c|c|c|c|c|c|}
\hline \multirow[t]{2}{*}{ Age Group } & \multicolumn{2}{|c|}{ Case } & \multicolumn{2}{|c|}{ Case } & \multirow[t]{2}{*}{ p-value } \\
\hline & Male & Female & Male & Female & \\
\hline$\leq 10$ Years & $2(4.0 \%)$ & $0(0.0 \%)$ & $1(2.0 \%)$ & $1(2.0 \%)$ & \\
\hline 11 to 20 Years & $16(32.0 \%)$ & $4(8.0 \%)$ & $6(12.0 \%)$ & $13(26.0 \%)$ & 0.273 \\
\hline 21 to 30 Years & $11(22.0 \%)$ & $13(26.0 \%)$ & $15(30.0 \%)$ & $4(8.0 \%)$ & \\
\hline 31 to 40 Years & $0(0.0 \%)$ & $2(4.0 \%)$ & $5(10.0 \%)$ & $2(4.0 \%)$ & \\
\hline$>40$ Years & $2(4.0 \%)$ & $0(0.0 \%)$ & $3(6.0 \%)$ & $0(0.0 \%)$ & \\
\hline Total & $31(62.0 \%)$ & $19(38.0 \%)$ & $30(60.0 \%)$ & $20(40.0 \%)$ & \\
\hline
\end{tabular}

Table 2: Demographic Data of Epilepsy Patients

\begin{tabular}{lcc}
\hline Variables & Case Group & Control Group \\
\hline Educational status & & \\
- Below Primary & $35(70.0 \%)$ & $29(58.0 \%)$ \\
- SSC & $7(14.0 \%)$ & $11(22.0 \%)$ \\
- Above SSC & $8(16.0 \%)$ & $10(20.0 \%)$ \\
Occupation & & \\
- Unemployed & $31(62.0 \%)$ & $26(52.0 \%)$ \\
- Employed & $19(38.0 \%)$ & $24(48.0 \%)$ \\
$\begin{array}{l}\text { Income status } \\
\text { - Low income group }\end{array}$ & $35(70.0 \%)$ & $18(36.0 \%)$ \\
- Middle income group & $15(30)$ & $32(64)$ \\
Residence & & \\
- Urban & $16(32.0 \%)$ & $28(56.0 \%)$ \\
- Rural & $34(68.0 \%)$ & $22(44.0 \%)$ \\
\hline
\end{tabular}

The table 5 shows that the presences of important past $\mathrm{H} / \mathrm{O} \mathrm{CNS}$ disorders are important risk factors for uncontrolled epilepsy. The difference was statistically significant $(p=0.004)$. Chi-square test was done to measure the level of significance.

Table 5: Distribution of patients according to previous history

\begin{tabular}{lccc}
\hline Previous history & Group & \multicolumn{2}{c}{ p value } \\
\cline { 2 - 3 } & Case & Control & \\
\hline H/O status epilepticus & $4(8.0 \%)$ & $1(2.0 \%)$ & \\
H/O perinatal insult & $7(14.0 \%)$ & $0(0.0 \%)$ & \\
H/O delayed mile stones & $6(12.0 \%)$ & $2(4.0 \%)$ & 0.004 \\
H/O CNS infection & $3(6.0 \%)$ & $1(2.0 \%)$ & \\
H/O significant head trauma & $5(10.0 \%)$ & $3(6.0 \%)$ & \\
No significant history & $25(50.0 \%)$ & $43(86.0 \%)$ & \\
Total & $\mathbf{5 0 ( 1 0 0 . 0 \% )}$ & $\mathbf{5 0 ( 1 0 0 . 0 \% )}$ & \\
\hline
\end{tabular}


Patients with partial seizures and mixed seizures tend to have uncontrolled epilepsy. The difference was not statistically significant $(\mathrm{p}=0.070)$. Chi-square test was done to measure the level of significance (Table 6).

Table 6: Distribution of patients according to type of initial seizure type

\begin{tabular}{lccc}
\hline \multirow{2}{*}{$\begin{array}{l}\text { Type of } \\
\text { Initial Seizure }\end{array}$} & \multicolumn{2}{c}{ Group } & p value \\
\cline { 2 - 3 } & Case & Control & \\
\hline Partial & $31(62.0 \%)$ & $21(42.0 \%)$ & \\
Generalized & $17(34.0 \%)$ & $29(58.0 \%)$ & 0.070 \\
Mixed & $2(4.0 \%)$ & $0(.0 \%)$ & \\
Total & $\mathbf{5 0}(\mathbf{1 0 0 . 0 \% )}$ & $\mathbf{5 0}(\mathbf{1 0 0 . 0 \% )}$ & \\
\hline
\end{tabular}

Presences of some associated features render the patient to the risk of uncontrolled epilepsy. The difference was statistically significant $(\mathrm{p}=0.030)$. Chi-square test was done to measure the level of significance (Table 7).

Table 7: Distribution of Patients According to Associated Clinical Feature

\begin{tabular}{lccc}
\hline Clinical Feature & \multicolumn{2}{c}{ Group } & \multirow{2}{*}{ p value } \\
\cline { 2 - 3 } & Case & Control & \\
\hline Neurological deficits & $9(18.0 \%)$ & $4(8.0 \%)$ & 0.030 \\
Behavioral abnormality & $15(30.0 \%)$ & $6(12.0 \%)$ & \\
Mental retardation & $2(4.0 \%)$ & $2(4.0 \%)$ & \\
Not significant & $24(48.0 \%)$ & $38(76.0 \%)$ & \\
Total & $\mathbf{5 0 ( 1 0 0 . 0 \% )}$ & $\mathbf{5 0 ( 1 0 0 . 0 \% )}$ & \\
\hline
\end{tabular}

Non-responders to first AEDs are at risk of uncontrolled epilepsy. The difference was statistically significant $(\mathrm{p}=0.005)$. Chi-square test was done to measure the level of significance (Table 8).

Table 8: Distribution of Patients According to Non-Response to First AED

\begin{tabular}{lccc}
\hline \multirow{2}{*}{$\begin{array}{l}\text { Non-response to } \\
\text { first AED }\end{array}$} & \multicolumn{2}{c}{ Group } & p value \\
\cline { 2 - 3 } & Case & Control & \\
\hline Yes & $28(56.0 \%)$ & $38(76.0 \%)$ & 0.001 \\
No & $22(44.0 \%)$ & $12(24.0 \%)$ & \\
Total & $\mathbf{5 0 ( 1 0 0 . 0 \% )}$ & $\mathbf{5 0 ( 1 0 0 . 0 \% )}$ & \\
\hline
\end{tabular}

Non availability of the AEDs leads to non-compliance and poor seizure control. The difference was statistically significant $(\mathrm{p}=0.001)$. Chi-square test was done to measure the level of significance (Table 10).
Table 10: Distribution of patients according to availability of drug

\begin{tabular}{lccc}
\hline \multirow{2}{*}{$\begin{array}{l}\text { Availability of } \\
\text { drug }\end{array}$} & \multicolumn{2}{c}{ Group } & p value \\
\cline { 2 - 3 } & Case & Control & \\
\hline Available & $19(38.0 \%)$ & $35(70.0 \%)$ & 0.001 \\
Not available & $31(62.0 \%)$ & $15(30.0 \%)$ & \\
Total & $\mathbf{5 0 ( 1 0 0 . 0 \% )}$ & $\mathbf{5 0}(\mathbf{1 0 0 . 0} \%)$ & \\
\hline
\end{tabular}

Intake of AEDs on time lead to a better control of seizure. The difference was statistically significant $(p=0.001)$. Chi-square test was done to measure the level of significance (Table 11).

Table 11: Distribution of patients according to intake of antiepileptic regularly on time

\begin{tabular}{lccc}
\hline \multirow{2}{*}{$\begin{array}{l}\text { Taking antiepileptic } \\
\text { regularly on time }\end{array}$} & \multicolumn{2}{c}{ Group } & p value \\
\cline { 2 - 3 } & Case & Control & \\
\hline Yes & $24(48.0 \%)$ & $49(98.0 \%)$ & 0.001 \\
No & $26(52.0 \%)$ & $1(2.0 \%)$ & \\
Total & $\mathbf{5 0 ( 1 0 0 . 0 \% )}$ & $\mathbf{5 0}(\mathbf{1 0 0 . 0} \%)$ & \\
\hline
\end{tabular}

A normal brain imaging is associated with better seizure control. The difference was statistically significant $(p=0.013)$. Chi-square test was done to measure the level of significance (Table 12).

Table 12: Distribution of patients according to brain imaging

\begin{tabular}{lccc}
\hline \multirow{2}{*}{$\begin{array}{l}\text { Brain } \\
\text { Imaging }\end{array}$} & \multicolumn{2}{c}{ Group } & p value \\
\cline { 2 - 3 } & Case & Control & \\
\hline Normal & $31(62.0 \%)$ & $42(84.0 \%)$ & \\
Abnormal & $19(38.0 \%)$ & $8(16.0 \%)$ & 0.013 \\
Total & $\mathbf{5 0 ( 1 0 0 . 0 \% )}$ & $\mathbf{5 0}(\mathbf{1 0 0 . 0 \% )}$ & \\
\hline
\end{tabular}

\section{Discussion}

Epilepsy is a common neurological disorder ${ }^{18}$. It is estimated that there are at least 1.5 to 2 million epilepsy patients in Bangladesh ${ }^{3}$. Many of these patients have uncontrolled epilepsy. The causes behind this uncontrolled epilepsy are multi factorial of which non-compliance is one of the important factors. Compliance behavior can be defined as taking anti-epileptic drugs (AEDs) on time, not manipulating dosages, and following the doctor's advice regarding daily activities ${ }^{4}$.

Studies regarding non-compliance have found four primary factors which are patient-related factors like socio-economic characteristics, and perceptions and beliefs, illness-related factors like severity of illness and frequency of symptom, medication related factors like number of daily doses, efficacy, and side effects, 
and physician-related factors like patient-physician relationship ${ }^{7,8}$.

In this present study a total number of 100 epilepsy patients were enrolled of which 50 patients were in the case group who presented with uncontrolled epilepsy and the rest 50 patients were in the control group who presented with controlled epilepsy.

Most of the patients were young ( $<30$ years) with a male preponderance in both groups. This indicates the relative homogeneity of case and control groups. Tran et al (2006) in their study also showed that the peak age of incidence was in children and young adults ${ }^{19}$. One study, done in Shanghai, showed two prevalence age peaks: one between 10 and 30 years old and another in people over 60 years old ${ }^{20}$. In developed countries, the incidence and prevalence of epilepsy both follow a bimodal distribution with a first peak in childhood and another in old age ${ }^{21}$. The most probable reason for the missing peak in the older age group in many Asian countries is relatively young population compared with that in more developed regions. The present study result indicates that male was more vulnerable than female. Similar result was reported by Mac et al (2007) and mentioned that epilepsy was slightly more common in men than in women ${ }^{21}$. However, the sex-specific prevalence is not, significantly different.

Unemployment has been found to be a risk factor for uncontrolled epilepsy probably due to the inability of the patient to buy AEDs. This study revealed that $21(42 \%)$ patients in case group and $7(14 \%)$ in the control group were unemployed. This study revealed that patients with lower level of education and those residing in the rural area, have more chance of having uncontrolled epilepsy than the educated patients and those living in urban areas probably because of their poor understanding or awareness about the disease. Patients with lower income have also been shown to have a poor control of epilepsy probably due to their inability to buy the AEDs. Similar result has been found in other studies ${ }^{21}$.

Earlier age at onset and higher initial seizure frequency have been identified as risk factor for uncontrolled epilepsy in this study. Sillanpaa found patients having refractory epilepsy had high initial seizure frequency ${ }^{22}$. In a recent study, a model comprising these variables (etiology, age at onset of epilepsy and number of seizures during first 6 months after diagnosis) had classified patients in groups with low, intermediate and high risk of refractory epilepsy ${ }^{23}$.

This study showed that patients with a previous history of status epilepticus, prenatal insult, delayed mile stones and significant head trauma are at risk of uncontrolled seizure. These findings are almost similar to those in other studies ${ }^{24-26}$.

Some associated clinical problems like neurological deficits, behavioral abnormality, and mental retardation have been shown to have poor control of epilepsy in this study ${ }^{27}$. Patients with abnormal brain image also had poor control of seizure which is consistent with other studies ${ }^{15}$.

Patients who responded well to their first AED had a better control of seizure in this study. So poor response to first AED is another risk factor for uncontrolled epilepsy. Good family support, easy availability of drugs, good initial motivation of the patient were other factors which lead to good control of seizure in patients in this study. International Bureau for Epilepsy (2011) has mentioned that causes for non-compliance in Bangladesh include non-affordability of drugs, limited availability of drugs, inadequate knowledge, negative attitude, lack of counseling, adverse effects of drug $^{3}$.

Limitation of this study were the small sample size and it was carried out in a single centre.

\section{Conclusion}

In conclusion, this study identified many factors behind the poor control or uncontrolled seizures like lack of support from the family, lack of motivation about the disease, unavailability of drugs, irregular intake of anti-epileptic drugs, stopping AEDs willingly after transient control of seizures, lack of knowledge about the disease, low annual income of the family, unemployment, lower educational status, residence in rural area, earlier age of onset of seizure, higher initial seizure frequency, associated clinical features (neurological deficits, mental retardation, behavioral abnormality, abnormal brain imaging findings, non response to first anti epileptic drug etc. Many of these factors can be minimized if proper counseling of the patient and their family is done at the time of initiation of treatment. The Government should ensure the supply of important antiepileptic drugs free of cost to the patient.

\section{References}

1.World Health Organization. Atlas: epilepsy case in the world 2005, Geneva: WHO Press 2005;1:11-3

2.Ngungi A, Bottomley C, Kleinschmidt I, Sander J, Newtor C. 2010. Estimation of the burden of active and lifetime epilepsy: a meta-analytic approach. Eplepsia 2010;51:883-90

3.International Bureau for Epilepsy (IBE). 2011. Epilepsy in Bangladesh: News and Updates, section regions, South East Asia, text pattern category import. Available from: http://www.ibe-epilepsy.org/epilepsy-in-bangladesh/

4.Leppik. How to get patient to take their medicine. Postgrad Med. 1990; 88(1): 253-5

5.Blackwell B. Treatment compliance. Kaplan and Sadock's 
comprehensive text book of psychiatry, 7th ed. Philadelphia: Lippincott Williams and Wilkins. 2000; 2: 1893-8

6.Henneman EA, Lee JL, Cohen JI. Collaboration: a concept of analysis. J Advanced Nursing. 1995; 21:103-9

7.Buck D, Jacoby A, Baker G A, Chadwick DW. Factors influencing compliance with antiepileptic drug regimes. Seizure. 1997; 6: 87-93

8.Scott J, Pape M. Nonadherence with mood stabilizer: prevalence and predictors. Jcoin Psychiatry. 2000; 63: 384-90

9.Dhanaraj M, Jayavelu A. 2004. Factors influencing Anti Epileptic Drug Non-Compliance. Annals of Indian Academy of Neurol 2004; 7(2): 369-74

10.Kyngaos H. 2001. Predictors of good compliance in adolescents with epilepsy. Seizure. 2001; 10: 549-53

11.Fisher R, Van Emde, Boas W, Blume W, Engl C, Genton P, Lee $P$ and Engel J . Epileptic seizure and epilepsy: definition proposed by the International League against Epilepsy and the International Bureau for Epilepsy (IBE). Epilepsy. 2005; 46(4): 470-2

12.Berg AT, Levy SR, Novotny EJ, Shinnar S. Predictors at Intractable epilepsy in child hood: a case control study. Epilepsia. 1996; 37(1) 24-30

13.Kwan P, Brodie MJ. 2000. Early identification of refractory epilepsy. N Engl J Med.2000; 342(5): 314-9

14.Kwong Kl, Sung WY, Wong SN, Sok T. Early predictors of medical intractability in child hood epilepsy. Pediatr Neurol.2003; 29 (1): 46-52

15.Gururaj A, Sztriha L, Hertecant J, Eapen V. Clinical predictors of intractable childhood epilepsy. J Psychosom Res. 2006 ; 61(3) :343-47

16.Camfield C, Camfield P, Gordon K, Smith B Dooley J.

Outcome of childhood epilepsy: A population-based study with a simple scoring system for those treated with medication. J Pediatr.1993; 122: 861-8

17. Chawla S, Aneja S, Kashyap R, MallikaV. Etiology and clinical Predictors of Intractable Epilepsy. Pediatr Neurol.2002; 27:186-91

18.Blume W, Luders H, Mizrahi E. Glossary of descriptive terminology for ictal semiology: report of the ILAE Task Force on classification and terminology. Epilesia.2001; 42(9):1212-18

19.Tran DS, Odermatt P, Le TO, et al. Prevalence of epilepsy in a rural district of central Lao PDR. Neuroepidemiol. 2006;26:199-206

20.Huang M, Hong Z, Zeng J. The prevalence of epilepsy in rural Jinshan in Shanghai. Zhonghua Liu Xing Bing Xue Za Zhi. 2002;23:345-6

21.Mac TL, Tran DS, Quet F, Odermatt P, Preux PM, Tan CT. Epidemiology, aetiology and clinical management of epilepsy in Asia: a systematic review. Lancet Neurol 2007; 6:533-43

22. Sillanpaa M. Children with epilepsy as adults: outcome after 30 years of follow-up. Acta Paediar Scand suppl 1990;368:1-78

23.Ramos-Lizana J, Aguilera-Lopez P, Aguirre-Rodriguez J, Cassinello-Garcia E. Early prediction of refractory epilepsy in childhood. Seizure 2009; 18(6): 412-16

24.Li SC, Schoenberg BS, Wang CC, et al. Epidemiology of epilepsy in urban areas of the People's Republic of China. Epilepsia. 1985 ; 26: 391-94

25.Hui AC, Kwan P. Epidemiology and management of epilepsy in Hong Kong: an overview. Seizure. 2004;13: 244-46

26.Rajbhandari KC. Epilepsy in Nepal. Neurol J Southeast Asia. 2003; 8:1-4

27.Devinsky O. Patients with refractory seizures. N Engl J Med.1999; 340:1565-70 